\title{
PROYECTO DE INVESTIGACIÓN DE LA FORMACIÓN DE DIALECTOS (FORDIAL)
}

\author{
Juan Andrés Villena Ponsoda*, Juan Antonio Moya Corral**, \\ antonio M. Ávila Muñoz*, Matilde Vida Castro* \\ * Universidad de Málaga \\ ** Universidad de Granada
}

\begin{abstract}
Resumen
The research project on Dialect Formation (DiALFOR) focuses on dialect contact between southern varieties of Spanish in urban contexts boosted by migration from the rural Hinterland in Andalusia in the course of the last thirty years. Either loyalty to rural vernacular varieties or convergence towards regional and national standard is constrained by the speakers' degree of integration into the large (urban) speech community. The analysis of the social networks where ordinary people live and communicate allows us to explain the speakers' choices.

To carry out this research, two sample surveys (Granada and Malaga) using the same fieldwork methodology and theoretical background have been prepared, where commuters and migrant citizens are separated. A third control group of speakers is studied in each rural community where migrants come from.

Theoretical foundations and empirical bases are taken from contemporary trends of European social dialectology research on dialect convergence and divergence (Auer/ Hinskens, 1996a; Mattheier, 2000), with special reference to studies on dialect formation in new towns (Kerswill, 1994a, 2002). Long term network research carried out on Malaga and Granada speech communities are taken as a point of depart (Villena, 1994, 2001; Moya, 1997, 1998).
\end{abstract}

\section{Introducción}

\subsection{Objetivo}

El Proyecto de Investigación sobre la Formación de Dialectos (FordiaL) es un estudio de la formación de variedades lingüísticas en los contactos producidos en los núcleos urbanos a consecuencia de los movimientos poblacionales ligados a la inmigración procedente de las áreas rurales ${ }^{1}$. Se trata de investigar la producción de procesos de nivelación (levelling) y de coinización (koineisation) y de analizar sus fundamentos y desarrollo a partir de las bases teóricas y metodológicas de las que se dispone (Auer y Hinskens, 1996a; Villena, 2001; Kerswill, 2002).

1 Agradecemos a Félix Requena Santos su revisión crítica de versiones previas de este trabajo. 
La hipótesis básica es que existen dos tendencias contrarias que subyacen en los procesos interdialectales: por un lado, la resistencia al cambio en el sistema y en los rasgos del vernacular de los hablantes rurales inmigrados a las ciudades; por otro lado, la acomodación a las variedades nuevas, ya sea al estándar (nacional o regional) o a las variedades concurrentes del mismo o parecido estatus, esto es, una especie de interlecto que se forma en tales situaciones. Las condiciones socioculturales, personales y familiares (ideología, economía doméstica, expectativas, etc.) influyen considerablemente en la actitud y en la conducta de dichos hablantes, pero el grado de integración social en la nueva situación es el aspecto más crucial. La investigación de las circunstancias personales tal y como se observan en las redes sociales de los hablantes es el medio más adecuado para explicar el mencionado grado de integración y, por tanto, la acomodación de los hablantes o, contrariamente, su lealtad al dialecto rural (Caravedo, 1990, 1996; Auer et alii, 2000; Villena, 2003). Se considera probable que cuando se producen contactos interdialectales las tendencias a la simplificación de los sistemas queden contrarrestadas por la nivelación en el sentido de los modelos ideales ejemplares, aunque ello suponga el desarrollo de distinciones más complejas.

Para comprobar esta hipótesis se investigan muestras por cuotas en dos ciudades de Andalucía (Granada y Málaga) de acuerdo con los criterios estandarizados. Estas muestras reflejan dos estadios diferentes de aclimatación de los inmigrantes rurales (commuters e instalados), de modo que el período de estancia es (junto a la edad, la educación y el sexo) una variable de estratificación ( $\$ 3.1$ ). Paralelamente, se desarrolla un estudio similar de control en las localidades rurales de origen de los inmigrantes estudiados en la ciudad.

La investigación de la formación de dialectos (ForDiaL) parte de los hallazgos previos en el estudio de los procesos de convergencia y divergencia dialectal centrados en los inmigrantes urbanos, especialmente en Europa (Nordberg (ed.), 1994; Auer y Hinskens (eds.) 1996a; Hernández Sacristán y Morant (eds.), 1997; Mattheier (ed.), 2000). Se basa, asimismo, en los trabajos reticulares sobre las variedades urbanas en Málaga (Ávila, 1994; Villena, 1994, 1996, 1997, 2000, 2001; Villena y Requena, 1996; Cuevas, 2001; Vida, 2003) y en Granada (Moya y García Wiedemann, 1995; Moya, 1997, 2000, 2003; Martínez y Moya, 2000).

\subsection{Proposiciones}

(1) A la vista de lo que hoy sabemos (Villena, 2000, 2001), los modelos urbanos de pronunciación del español en Andalucía son el español estándar meridional (EM), esto es, el estándar nacional teñido de rasgos meridionales, y un estándar regional andaluz (ER) más alejado de los modelos nacionales. El ER tiene como ejemplo el sociolecto de las clases acomodadas de Sevilla y está apoyado por los medios de comunicación regionales. El EM, por el contrario, fija como referencia el español estándar (EE) y se extiende fuera de las fronteras geográficas de Andalucía, manifestándose como próximo a la lengua común en registro poco planificado, poco técnico y en estilos informales (Umgangsprache). La dirección que toman los interlectos inmigrantes en uno u otro sentido depende de la existencia de un centro cultural, social o político de tipo regional o local y del valor otorgado en el área y por los propios hablantes a dicho centro. Los datos a nuestro alcance (cfr. Villena, 1997, 2000) nos hacen pensar en movimientos coinéticos occidentales influidos o sancionados por el prestigio de las variedades urbanas de la ciudad de Sevilla. La inexistencia de un centro similar a Sevilla hace esperable que los contactos interdialectales en 
Granada y Málaga hayan producido un acercamiento al EM entre los inmigrantes de origen rural $(\S 2.1)$.

(2) El grado de acomodación de los hablantes rurales a las variedades ejemplares (nivelación) y a los demás dialectos (coinización) depende de la duración del período de estancia en la ciudad y del grado relativo de lealtad a la localidad de origen. La estructura de las redes sociales de los hablantes inmigrados en las ciudades y su grado de apertura al exterior es un factor que influye decisivamente en la elección de los modelos ideales de comportamiento lingüístico. Las redes densas y las comunidades locales cerradas favorecen la conservación de las estructuras del vernacular de origen, en tanto que las redes sueltas o laxas y las comunidades más abiertas al exterior favorecen la integración en el tejido urbano y la adopción de rasgos de compromiso interdialectal y/o del estándar. Los patrones más divergentes y minoritarios de pronunciación se correlacionan estrechamente con los marcadores reticulares que indican unión fuerte y solidaridad $(\S 2.2)^{2}$.

(3) La educación formal y la edad (en interacción con el sexo) condicionan las expectativas de movilidad social de los hablantes y se concretan en su estatus y en su relación con la información. En la sociedades urbanas los individuos jóvenes e informados (sean masculinos o femeninos) abandonan progresivamente las familias extensas y forman redes sociales de muchos lazos y poca intensidad. Este proceso supone el abandono de los valores de los padres y la adopción de las normas nuevas. El comportamiento lingüístico refleja con claridad este proceso. En particular, se ha observado un movimiento de convergencia de los hablantes jóvenes que tiene como referencia los modelos ideales de las variedades ejemplares urbanas $(\S 2.3)$.

\section{Antecedentes}

\subsection{La estructura de la comunidad de habla}

Las comunidades de habla y, por lo tanto, los hablantes que las constituyen pueden representarse (los podemos imaginar) como continuos o, mejor, gradata de variación que dependen o están condicionados por conjuntos multifactoriales. De entre estos factores condicionantes, la dimensión del prestigio es una de las más importantes, puesto que, en realidad, es la expresión superficial de varias dimensiones subyacentes. La conducta lingüística de los hablantes se organiza bien en función del prestigio de corriente dominante (llamado patente u overt prestige), bien en función de otro tipo de prestigio (denominado latente, en-

2 La integración de los inmigrantes en el nuevo medio (comunidad de habla urbana) es una función de su actitud ante la vida urbana y, respectivamente, de su lealtad a los valores de la comunidad local de origen. La observación de las redes sociales de los hablantes y el estudio de sus propiedades es el procedimiento más adecuado para estudiar la penetración de las corrientes urbanas en las comunidades de inmigrantes rurales y su progresiva separación del contexto originario. La investigación de Bortoni-Ricardo (1985) en Brazlândia demostró la base reticular de la dispersión dialectal en la variedad rural de los inmigrantes y se centró, en particular, en los procesos de convergencia en el sentido del estándar (nivelación). Al estudio de estos procesos se pretende añadir ahora la consideración de los procesos de convergencia interdialectal (simplificación) que conducen a la coinización. Además, en nuestro caso particular entran en juego, asimismo, otros factores demográficos y geolingüísticos que influyen en la potenciación del estándar regional como alternativa prestigiosa al estándar nacional. 
cubierto o covert prestige). El primero se relaciona con lo institucional, formal o referencial; el segundo, con la vida diaria, las relaciones informales y la experiencia.

En consecuencia, constatamos la distinción entre dos polos opuestos (correspondientes a valores opuestos) de un continuo de variación lingüística (Figura 1):

(i) por un lado, las variedades vernaculares (v), utilizadas por los hablantes en relación directa con los valores del prestigio encubierto y con las redes de relaciones informales con los amigos, los parientes, los vecinos y los compañeros de trabajo;

(ii) por otro lado, la variedad ejemplar o estándar (E), propia de valores, ambientes y relaciones institucionales o formales (prestigio patente).

Los hablantes usan los rasgos vernaculares (v) o estándar (E) y refuerzan su significado social en función de sus propias circunstancias personales o colectivas. La distribución social de los rasgos permite hablar en muchas ocasiones de variedades (así, la variedad $v$ con los rasgos $x, y, z$, distribuidos con la frecuencia $n$ en el grupo $G$, estilo $K$, área $A$, etc.), de ahí que nos hayamos referido antes a un gradatum de variación, si bien lo que tenemos idealmente es un continuo de variación.

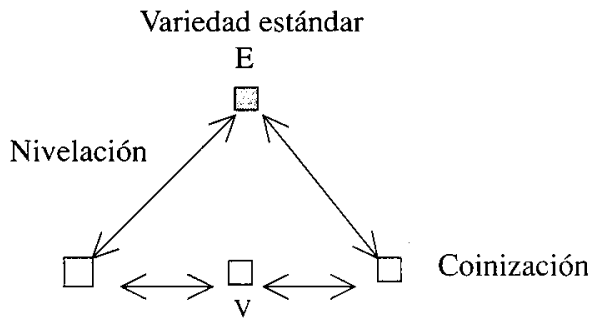

Variedades vernaculares

Figura 1. Continuo de variación

Las variedades vernaculares concentradas (esto es, regulares y con reglas categóricas) se mantienen si las circunstancias sociales y económicas de la comunidad (apertura) y la morfología de las redes sociales de sus hablantes (densidad) lo potencian; esto es, si la comunidad es cerrada y las redes densas (Trudgill, 1996). Conforme la comunidad se abre al influjo de corriente dominante y las redes se aflojan, las variedades vernaculares entran en contacto entre sí (por ejemplo, en los barrios de inmigrantes de las ciudades) y con las variedades superpuestas (Trudgill, 1986; Mattheier, 1996; Kerswill, 2002). Esto propicia dos movimientos distintos (Figura 1):

$1 .^{\circ}$ La convergencia horizontal entre las variedades vernaculares (coinización). Las variedades se aproximan y se simplifican, optando por las soluciones más simples y menos marcadas (Auer, 1988; Hinskens, 1996; Kerswill, 1994a, 1996). Este es el movimiento característico de la formación de los dialectos meridionales del español en la Edad Media que se produce cuando no existe un modelo ideal indiscutible de prestigio (Mondéjar, 1991; Frago, 1993).

$2 .^{\circ}$ La convergencia vertical en el sentido de la variedad estándar (nivelación). Las variedades convergen en la medida en que convergen en el sentido del modelo ideal nacional de prestigio. Las soluciones entonces no son necesariamente las más simples (Auer y Hinskens, 1996a). 
Que se imponga uno u otro de los movimientos (o que, contrariamente, se mantenga el aislamiento y la concentración vernacular) depende de una serie de condicionamientos de distinto tipo: factores de integración (2.1.1); factores estructurales o funcionales (2.2.2) y factores demográficos o geolingüísticos (2.3.3).

\subsubsection{Factores de integración}

Los factores de integración definen el tipo de comunidad (abierta / cerrada) en combinación con el tipo predominante de red social (densa / laxa). Cuando se da la combinación más favorable al ensimismamiento (redes densas y comunidad cerrada), la concentración se extrema y, a la inversa, cuando se da la combinación más favorable a la convergencia (redes laxas y comunidad abierta), las variedades se dispersan (Cuadro 1). Según Trudgill (1996: 12), estas combinaciones dependen de dos parámetros: (1) el parámetro del contacto (que favorece / desfavorece el desarrollo de rasgos lingüísticos que benefician al hablante / oyente en función del grado bajo/alto de contacto de los integrantes de la comunidad de habla); (2) el parámetro de la red social (que influye en la mayor/menor probabilidad de aparición de rasgos lingüísticos en función del tipo morfológico de red social de la comunidad de habla).

\section{CUADRO 1}

Tipología reticular y tipo de comunidad de habla. Modelo de predicción del uso vernacular. Adaptado de Trudgill (1996: 3-4)

\begin{tabular}{|c|l|l|}
\hline & \multicolumn{2}{|c|}{ TIPO DE COMUNIDAD DE HABLA } \\
\hline TIPOLOGIA DE LA RED & BAIO GRADO DE CONTACTO & Alto GRADO DE CONTACTO \\
\hline densa & $\begin{array}{l}\text { (A) concentración vernacular: } \\
\text { divergencia frente al estándar }\end{array}$ & $\begin{array}{l}\text { (B) concentración elitista: } \\
\text { uso 'legítimo' del estándar }\end{array}$ \\
\hline laxa & (c) variación anómica & $\begin{array}{l}\text { (D) dispersión vernacular: } \\
\text { convergencia hacia el estándar }\end{array}$ \\
\hline
\end{tabular}

Los dos tipos extremos de comunidad: comunidades con bajo grado de contacto y red densa con variedades vernaculares muy regulares (A) y comunidades con alto grado de contacto y red laxa con variedades niveladas o difusas (D) constituyen los dos polos de un continuo de variación con varios tipos intermedios (infra, Cuadro 2) ${ }^{3}$. La hipótesis de Trudgill consiste en afirmar que puede existir una correlación entre el tipo comunitario y la tendencia al uso de determinados rasgos fonológicos (véase Cuadro 2); en particular, la simplificación / complejidad del repertorio fonológico y la aceptación / freno de las tendencias naturales a la facilidad de pronunciación (cfr. Kroch, 1978):

3 Los tipos intermedios incluidos en el Cuadro 1 tienen muy diferente incidencia en las comunidades de habla: el tipo 8 es bastante corriente entre las clases altas, que disponen de redes laxas con muchos lazos débiles en el dominio del trabajo y de redes densas y muy intensas en el dominio familiar (efr. Milroy y Milroy, 1992). La combinación que define el tipo $c$ es inusual y podría corresponderse con concentraciones de actores sociales marginados. Ejemplos de los tipos pueden consultarse en los mencionados trabajos de Trudgill $(1992,1996,2002)$. 
a) Las comunidades del tipo A o de bajo contacto y estructura reticular densa son comunidades "volcadas al hablante": dada la alta cohesión reticular, hay un elevado grado de conocimiento entre los miembros y una constante referencia al contexto inmediato. Por eso, el equilibrio hablante/ oyente en el parámetro del contacto se decanta en el sentido del hablante; ejemplos de ello son los cambios lingüísticos naturales relacionados con el habla rápida o las reducciones fonéticas en los estilos contextuales informales (Dressler y Wodak, 1982; Trudgill, 1974: 178-185). Por su lado, el parámetro de la red condiciona la frecuencia de fenómenos no naturales de refuerzo y de complejidad alofónica, en el sentido de que la cohesión interna de la red de nudos apretados se asocia con frecuencia a estructuras fonológicas más complejas y más difíciles, aunque ello suponga un cierto coste antieconómico. Los refuerzos consonánticos en comunidades marginales (por ej., las consonantes parásitas del romanche estudiadas por Andersen (1988) o la complejidad alofónica del sistema vocálico del inglés de Belfast frente a la regularidad propia del inglés estándar comparadas por J. Milroy (1992: 55-60, 81-162 et passim) suponen un coste para el hablante que, sin embargo, se recompensa al establecerse una distancia frente a la comunidad vecina o rival (principio de neighbour opposition) ${ }^{4}$.

b) Las comunidades del tipo D o de alto grado de contacto externo y estructura reticular laxa son comunidades más equilibradas en la relación entre el hablante y el oyente, esto es, comunidades "de diálogo" en las que las condiciones de apertura al exterior y la variedad de contactos con hablantes no nativos aconsejan frenar las tendencias naturales a la facilidad de pronunciación (habla rápida en estilos informales) y, en menor medida, a la simplificación del repertorio. El oyente no nativo resulta perjudicado por las asimilaciones y reducciones fonéticas del habla rápida y por las fusiones y simplificaciones excesivas, la complejidad alofónica y la longitud de las palabras ${ }^{5}$. No obstante, el equilibrio sugerido en el parámetro del contacto garantiza al hablante cierta facilidad de pronunciación y propicia algunos fenómenos de descomposición o pérdida de rasgos, comodidad que restringe, por ej., los fenómenos de refuerzo no naturales que perjudican al hablante nativo ${ }^{6}$.

\subsubsection{Factores estructurales y funcionales}

Los factores estructurales y funcionales son la relativa proximidad o distancia entre los sistemas en contacto (horizontal o vertical); la mayor o menor proximidad facilita o dificulta la convergencia. El acercamiento entre los sistemas muy emparentados se produce siguiendo las soluciones más naturales y más simples. Como estableció Trudgill (1986), las variantes marcadas tienden a ser menos frecuentes en las mezclas (mixing) o a desaparecer en las fusiones o amalgamas (fudgings).

4

Cfr. Trudgill (1996: 17-18).

5 Por ej., la retención de $/ \mathrm{h} /$ o la resistencia a las fusiones $(/ \mathrm{f} /=/ \theta /, / \mathrm{J} /=/ \partial \mathrm{v} /$, que son normales en las variedades vernaculares y están ausentes en el inglés estándar; en esta última variedad -de alto grado de contacto-se evitan en lo posible las asimilaciones y reducciones fonéticas propias del habla rápida y que son frecuentes en los estilos informales; se beneficia, por el contrario, la regularidad alofónica en el vocalismo y la frecuencia de uso de los estilos formales (cfr. Trudgill, 1996: 14-15).

6 Por ej., la ausencia de refuerzos y adiciones en la estructura segmental que, más bien, se manifiesta en la pérdida de rasgos en los segmentos (v. gr. ingl. 'bet $\rightarrow$ 'be? $\varepsilon$, better 'mejor'). Compárese, a modo de contraste, el refuerzo consonántico del romanche: fkregver 'escribir', krekfia 'sierra', voks 'vosotros', etc. (Andersen, 1988). 


\section{CUADRo 2}

Tipología de comunidades de habla, parámetros y tendencias de correlación con fenómenos fonológicos. Adaptado de Trudgill (1996). Diacronía: 1, 2, 3; sincronía: 4, 5, 6.

\begin{tabular}{|c|c|c|c|c|}
\hline \multirow{2}{*}{$\begin{array}{c}\text { TIPO de } \\
\text { COMUNIDAD }\end{array}$} & \multicolumn{2}{|c|}{ Cerrada / Redes Densas } & \multicolumn{2}{|c|}{ Abierta / Redes Laxas } \\
\hline & $\begin{array}{l}\text { Parámetro } \\
\text { DEL CONTACTO }\end{array}$ & $\begin{array}{c}\text { PARÁmETRO } \\
\text { DE LA RED }\end{array}$ & $\begin{array}{l}\text { PARAMETRO DEL } \\
\text { CONTACTO }\end{array}$ & $\begin{array}{c}\text { PARÁMETRO DE } \\
\text { LA RED }\end{array}$ \\
\hline $\begin{array}{l}\text { FENÓMENOS } \\
\text { LINGÜISTICOS }\end{array}$ & Bajo contacto & Red densa & Alto contacto & Red laxa \\
\hline $\begin{array}{l}\text { 1. Refuerzos no } \\
\text { naturales }\end{array}$ & & $\begin{array}{l}\text { Sí } \\
\text { Cohesión } \\
\text { reticular }\end{array}$ & $\begin{array}{c}\text { No } \\
\text { Perjuicio al } \\
\text { hablante nativo }\end{array}$ & No \\
\hline 2. Habla rápida & $\begin{array}{c}\text { Sí } \\
\text { Beneficio al } \\
\text { hablante no } \\
\text { nativo }\end{array}$ & & $\begin{array}{c}\text { No } \\
\text { Perjuicio al } \\
\text { oyente no } \\
\text { nativo }\end{array}$ & \\
\hline $\begin{array}{l}\text { 3. Fusiones y } \\
\text { simplificaciones }\end{array}$ & & No & $\begin{array}{c}\text { Sí/No } \\
\text { Beneficia/perjudica } \\
\text { al hablante/oyente } \\
\text { no nativo }\end{array}$ & \\
\hline $\begin{array}{l}\text { 4. Complejidad } \\
\text { alofónica }\end{array}$ & & $\begin{array}{c}\text { Sí } \\
\text { Integración } \\
\text { reticular }\end{array}$ & $\begin{array}{c}\text { No } \\
\text { Oyente }\end{array}$ & $\begin{array}{c}\text { No } \\
\text { Diversificación } \\
\text { reticular }\end{array}$ \\
\hline 5. Habla rápida & $\begin{array}{c}\text { Sí } \\
\text { Hablante: } \\
\text { estilo informal }\end{array}$ & r & $\begin{array}{c}\text { No } \\
\text { Oyente: } \\
\text { estilo formal }\end{array}$ & \\
\hline $\begin{array}{l}\text { 6. Longitud de } \\
\text { palabras }\end{array}$ & & Sí & No & No \\
\hline
\end{tabular}

Las variedades occidentales del español andaluz están más alejadas del español estándar de hoy y de los dialectos regionales centrales y septentrionales sobre los que este último se estableció (Villena, 2001). Frente a las variedades orientales, las occidentales usan patrones de pronunciación divergentes que incluyen elevadas frecuencias de uso de fricativas palatales [j] y [z] ('telo 'techo', 'rozo, 'rollo') coexistentes con fricativas dentales no sibilantes

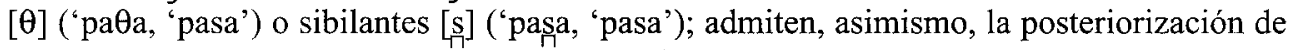
las fricativas dentales: $\theta^{\text {s }} \rightarrow \mathrm{h}$ ('paha, 'pasa') y la elisión de $/ \mathrm{h} /$ ('pa-a, 'paja'), así como otros cambios en cadena (Villena, 2001, 2002). Algunas de estas pautas se desarrollan con alta frecuencia y tienen un alto grado de aceptación social, penetrando en las capas sociales elitistas (Carbonero, 1983, 1992). Por el contrario, las variedades orientales usan patrones menos divergentes y con grados menores de aceptación (Moya Corral y G. Wiedemann, 1995; Molina Serrato y Moya Corral, 2002; Moya Corral, 2003; Molina Serrato, 2003). 


\subsubsection{Factores demográficos y geolingüísticos}

Los factores demográficos se concretan en la jerarquía del prestigio asociado a las variedades que puede determinar la dirección de la convergencia. Si existe una fuente regional de prestigio alternativa al estándar nacional (Figura 2), la formación de coinés da lugar al desarrollo de variedades estándar regionales (R) diferenciadas del estándar nacional $(\mathrm{E})$ o de su forma regional (EM). Si dicho centro de prestigio regional no existe o no tiene carácter indiscutible, la convergencia termina en una nivelación vertical (Figura 3).

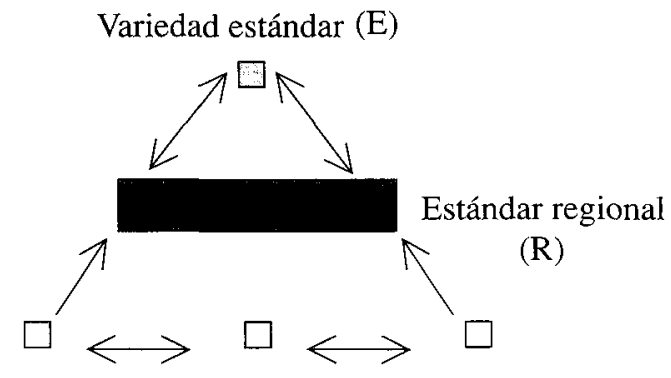

Variedades vernaculares (V)

Figura 2. Formación del estándar regional

Tenemos, por lo tanto, en primer lugar (Figura 2), un continuo de variación con una discontinuidad que ocupa una variedad relativamente concentrada: el modelo ideal regional (R), que sirve de variedad superpuesta ligada a los valores regionales (Carbonero, 2003). Entre esta variedad y el estándar nacional (E) discurre un continuo parcialmente difuso en el que se usan formas mixtas del estándar nacional (acento meridional; estándar teñido de regionalismos, etc.). En segundo lugar (Figura 3), encontramos un continuo convergente parcialmente difuso entre dos variedades concentradas ( $\mathrm{y} \mathrm{V}$ ), pero no existe una variedad regional claramente identificada.

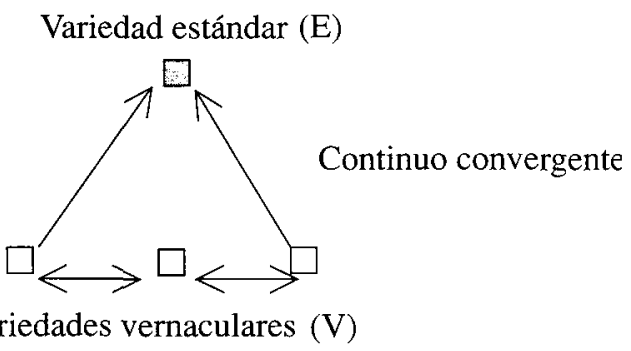

FIGURA 3. Formación del continuo convergente

La conjunción de los factores reseñados hasta aquí nos hace pensar en una configuración de estándar regional (Figura 2) en las áreas occidentales del español andaluz, cuyo vernacular está más distanciado del español estándar, como se dijo arriba. A ello se añade la fuerte 
influencia de la llamada norma sevillana. Por el contrario, en las áreas orientales y, en menor medida, centrales la influencia del ER es menor y la menor distancia estructural con respecto al estándar nacional favorece la convergencia en el sentido de este último (Figura 3$)^{7}$.

\subsection{Los límites de la integración: patrones divergentes de pronunciación}

La integración de los inmigrantes rurales en la estructura urbana depende de varios factores sociodemográficos (educación, grado de exposición a los medios de comunicación, ocupación, renta, etc.) y reticulares (redes densas y múltiples). Los hablantes con fuertes lazos de unión con la localidad de origen refuerzan su lealtad a los valores propios y rechazan los nuevos. La educación y, en general, el acceso a la información en el nuevo contexto favorecen el aflojamiento de las redes y el progresivo abandono de los rasgos dialectales ligados a la lealtad vernacular.

Los patrones de pronunciación de estos hablantes rurales se basan en modelos ideales innovadores con solo dos palatales $/ \mathrm{t} / / \mathrm{y} / \mathrm{j} / \mathrm{y}$ una fricativa dental $/ \theta^{s} /$ de amplio campo de dispersión. La variabilidad de los sistemas fonológicos meridionales provoca el desarrollo de patrones minoritarios altamente divergentes junto a los mayoritarios, menos proclives a las reducciones y a los cambios en cadena. Los patrones divergentes minoritarios presentan, entre otros fenómenos, los arriba mencionados de posteriorización de la fricativa dental / $\theta^{\mathrm{s} /}$ y elisión de la velar $/ \mathrm{h} /$.

Un ejemplo característico es el de la elisión de la consonante obstruyente velar $/ \mathrm{h} / \mathrm{En}$ Málaga, por ej., dicha variable se estratifica con una clara tendencia a la polarización por clases sociales (Tabla 1). El grado de integración del hablante en la comunidad de habla es decisivo: la "Escala de Integración" usa como indicadores la educación del hablante (0-3), su grado de exposición a los medios de comunicación (0-3) y el grado de deslealtad local (03). El resultado es una escala de 0-9 puntos en la que la máxima puntuación corresponde a la mayor apertura al exterior. Se supone que los hablantes mejor informados, más instruidos y con menos vinculaciones a los valores locales y más ligados a los valores de proyección comunitaria amplia tienen más contactos con el exterior ${ }^{8}$.

Como es de suponer, el comportamiento lingüístico de los hablantes puede predecirse a partir de su situación en escalas de este tipo que miden la posición del individuo en el mercado social y lingüístico. En la Tabla 1 se han incluido las probabilidades medias de la variable vernacular correspondiente a la elisión (te[ $] \mathrm{a},[\theta] a[\cdot] a r)$ de la consonante fricativa velar habitualmente realizada como una aspiración $[\mathrm{h}]$ en $t e[\mathrm{~h}] a$ 'teja' o $[\theta] a[\mathrm{~h}] a r$, 'sajar'. Si los argumentos explicados arriba son ciertos, la elisión probable de $/ \mathrm{h} /$ será mayor entre los hablantes más aislados que entre los más integrados en la comunidad amplia. Este hecho se confirma si tenemos en cuenta que la correlación de Spearman entre la probabilidad

Para todo ello, cfr. Mondéjar (1995) y Villena (1997, 2000, 2001).

8 Se comprueba esta afirmación acerca de que existe una relación entre el grado de contacto externo de los hablantes y la estructura de la red social, en el sentido de lo expuesto arriba (2.1.1 y Cuadro 1), cuando se observa que la media de la puntuación individual en la IR o "escala de intensidad reticular" (0-1) varía significativamente en función de la puntuación obtenida en la mencionada "escala de integración" reducida al efecto (0-1). Los hablantes que tienen menos contactos externos tienen vínculos reticulares más fuertes. Los hablantes con mayor número de contactos externos tienen vínculos más débiles en su red social. La diferencia es significativa. Véase a este respecto, infra, § 2.3. 
individual de elisión de la $/ \mathrm{h} / \mathrm{y}$ la puntuación individual en la "escala de integración" es relativamente fuerte, negativa y significativa $(-0.602, \mathrm{p}=0.000, \mathrm{~N}=113)$.

\section{TABLA 1}

Relación entre la estratificación social, el grado de integración del hablante en la comunidad de habla y las probabilidades de elisión de /h/ ('ko*o 'cojo', ko. 'e 'coger') en la ciudad de Málaga

\begin{tabular}{|l|c|c|c|c|c|}
\hline Clases sociales & $/ \mathbf{x} / \rightarrow \varnothing$ & $\mathbf{N}$ & Integración & $/ \mathbf{x} / \rightarrow \varnothing$ & $\mathbf{N}$ \\
\hline CB & $.52 \pm .26$ & 34 & 0 Grado bajo & $.42 \pm .27$ & 68 \\
CTB & $.31 \pm .24$ & 37 & I Grado alto & $.10 \pm .12$ & 45 \\
CTA & $.09 \pm .11$ & 33 & & & \\
CMB & $.10 \pm .12$ & 09 & & & \\
& & Chi $2=46.5552$ & & Sig. 0000 & \\
& & Sig. .0000 & & & \\
& & & & & \\
\end{tabular}

$N=113$; Св: Clase Baja; Ств: Clase Trabajadora Baja; CTA: Clase Trabajadora Alta; CMB: Clase Media Baja Para la significación de las diferencias de clase social se ha aplicado la prueba no paramétrica de Kruskall-Wallis. Para las diferencias debidas al distinto grado de integración se ha aplicado la prueba no paramétrica de MannWhitney

La integración de los hablantes en la vida urbana a partir de sus antecedentes personales y familiares es, asimismo, un factor influyente. Se supone que el hablante de origen familiar rural está incluido en redes sociales densas y múltiples conectadas con la localidad de origen. Esta situación puede durar bastante tiempo entre los inmigrantes, pero la fidelidad a esas redes es inversamente proporcional a la educación formal (considerada esta como un indicador de integración en las redes urbanas diversificadas o de nudos flojos). La "Escala de ruralidad" es el resultado de la recodificación (0-2) a partir de la escala original de 6 puntos": cuanto más alto se puntúa en la escala más relación tiene un hablante con su localidad rural de origen (o la de su familia) y menos instrucción formal ha recibido y a la inversa (Tabla 2). Por su parte, la relación entre las variables fonológicas y la escala de ruralidad (0-6) medida mediante el coeficiente de Spearman es relativamente fuerte y significativa ${ }^{10}$.

Como es de esperar, los hablantes menos integrados en el tejido urbano, con actitudes negativas hacia los contactos externos a su propia comunidad local y más relacionados con su localidad rural de origen, se mantienen leales a los patrones innovadores minoritarios que incluyen, en este caso, la posteriorización de $/ \theta^{\mathrm{s}} / \rightarrow[\mathrm{h}]$ ('meha 'mesa') y la elisión de $/ \mathrm{h} /$, ya mencionada arriba (ka'on 'cajón').

9 La "escala de ruralidad" (0-6) proviene de la suma de la puntuación individual, respectivamente, en el indicador inverso de educación formal (0-3) y en la "escala de intensidad reticular" (IR, 0-3). Esta última mide la fuerza de los vínculos de la red personal de los hablantes (cfr. Villena y Requena 1996).

10 La correlación de Spearman entre la Escala de Ruralidad (0-6) y las probabilidades de elisión de /h/ y de posteriorización de $/ \theta^{s} /$ no es extremadamente fuerte $(0.5849, \mathrm{n}=79$ y $0.5675, \mathrm{n}=84$, respectivamente), pero sí significativa en los dos casos $(p=0.000)$. 


\section{TABLA 2}

Diferencias de ruralidad en la elisión de $/ \mathrm{h} / \mathrm{y}$ la posteriorización de / $\theta^{\text {s/ en Málaga }}$

\begin{tabular}{|l|c|c|}
\hline Grado de Ruralidad & $\mathbf{h} \rightarrow \varnothing$ & $/ \theta^{\mathrm{s}} \rightarrow \mathbf{h}$ \\
\hline 0 & .10 & .00 \\
1 & .30 & .01 \\
2 & .48 & .08 \\
$\mathrm{Chi}^{2}$ & 28.5881 & 8.7782 \\
$\mathrm{Sig}$. & .0000 & .0003 \\
\hline
\end{tabular}

$\mathrm{N}=112$

Para la significación de las diferencias de ruralidad se ha aplicado la prueba no paramétrica de Kruskall-Wallis

\subsection{El deseo de acomodación: patrones convergentes}

Se trata de la situación contraria a la descrita en la sección anterior. Los hablantes que desarrollan su actuación lingüística en comunidades locales abiertas y con parámetros reticulares típicamente urbanos (redes laxas y diversificadas con vínculos poco intensos) se sienten atraídos por los modelos ideales conservadores en los que se basa el estándar nacional. Son hablantes jóvenes, con instrucción media o superior, bien informados y de profesiones prestigiosas. En consecuencia, muestran patrones convergentes a partir de los sistemas innovadores de partida; el resultado es la formación de variedades de aprendiz (learner's varieties) que aquí se manifiestan, sobre todo, en los patrones de distinción de $/ \mathrm{s} /: / \theta /$ mediante la oposición entre dental sibilante $[\mathrm{s}]$, 'tasa 'tasa', y dental no sibilante $[\theta]$, 'ta日a 'taza' (Tabla 3)'.

\section{TABLA 3}

Relación entre el uso del patrón convergente EM y el grado de integración en la comunidad de habla amplia en una red social de Capuchinos (Málaga).

Fuente: Ávila (1994); Villena (2003)

\begin{tabular}{|l|c|c|c|}
\hline $\begin{array}{l}\text { Integración en la } \\
\text { comunidad de habla }\end{array}$ & $/ \mathbf{s} /: / \theta /$ & $\mathbf{N}$ & IR \\
\hline 0 Grado bajo & $.33 \pm .31$ & 13 & $0.69 \pm 0.48$ \\
1 Grado alto & $.73 \pm .25$ & 16 & $0.33 \pm 0.49$ \\
& $\mathrm{Chi}^{2}=9.7651$ & & Sig. 0.050 \\
\hline
\end{tabular}

IR: Escala de Intensidad Reticular

Se ha comprobado la significación de las diferencias mediante la prueba de Mann-Whitney

Como se puede observar en la Tabla 3, los hablantes que viven fuertemente conectados a sus redes personales y, por tanto, desarrollan pocos vínculos externos $(\mathrm{IR}=0.69)$ no suelen adquirir la distinción del EM que es ajena a su vernacular de origen. Por el contrario, los 
hablantes jóvenes con instrucción media o superior y menos unidos a la comunidad local de sus mayores ( $\mathrm{IR}=0.33$ ) adquieren con frecuencia la mencionada distinción de sibilantes, al menos en las variedades orientales, como la de la ciudad de Málaga. Los datos de Granada apuntan en el mismo sentido (Moya y García Wiedemann, 1995; Moya, 1997, 1998; Martínez y Moya, 2000).

\section{Muestra y cuestionario}

\subsection{Variables independientes de estratificación}

Para comprobar las hipótesis sobre los procesos de formación de dialectos considerados en la sección previa se ha diseñado una muestra de hablantes basada en la procedencia y en la duración de la residencia de estos en la ciudad (rural, rurbano, urbano), en la edad, el sexo y el nivel educacional. Estas son, pues, las variables de estratificación en el presente estudio. Se siguen los criterios establecidos en el Proyecto de Investigación del Español de España y de América, PRESEEA (Moreno Fernández, 1993, 1996), que suponen un muestreo por cuotas con afijación uniforme (López Morales, 1994: 52-60); esto es, se divide el universo en estratos en función de las variables de estratificación y se asigna igual número de hablantes a cada cuota (para cada sexo se seleccionan cuatro hablantes en cada casilla). Se facilita así la comparación estadística y se evitan sesgos y otros efectos indeseables (Cuadro 3).

CuAdro 3. Estratificación de la muestra del Proyecto Fordial

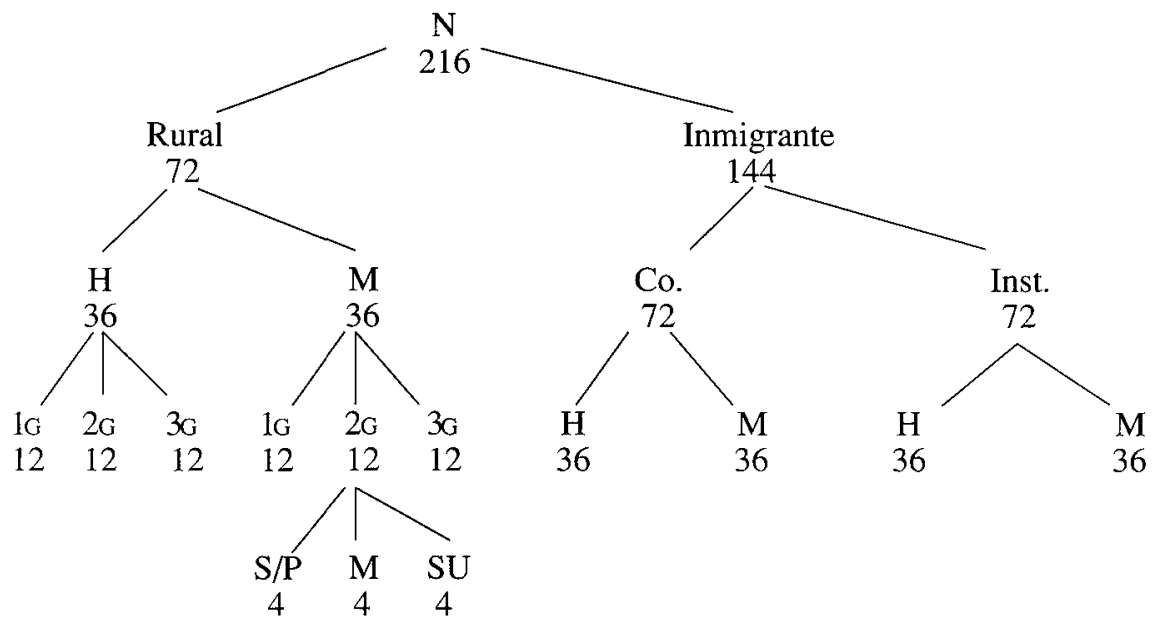

Rur.: Hablantes residentes en localidad rural Inm.: Inmigrantes residentes en localidad urbana Co.: Commuters: hablantes que realizan el trayecto pueblo-ciudad diariamente Inst:: Instalados: Hablantes de origen rural con residencia en la ciudad $H$ : Hombre; $M$ : Mujer l(i: 15-24 años; 2G: 25-54 años; 3G: > 54 años $\mathrm{s} / \mathrm{P}$ : Sin estudios / Primaria; M: Media; su: Superior 
Así pues, el total de informantes es de $\mathrm{N}=216(\mathrm{H}=108$ y $\mathrm{M}=108)$ para las tres muestras diseñadas, cada una de las cuales tiene un total de $\mathrm{N}=72$ hablantes $(\mathrm{H}=36 ; \mathrm{M}=36)$ : rural de control $(\mathrm{N}=72)$, inmigrantes instalados $(\mathrm{N}=72)$ y commuters $(\mathrm{N}=72)$. Se supone -como se indicó- que la duración del contacto en la ciudad es un factor decisivo en los procesos que se estudian. Por esta razón, se ha dividido el grupo de inmigrantes en instalados y commuters (véase el Cuadro 4). Actualmente se trabaja ya con grupos de inmigrantes de Alhama y Pinos Puente (Granada) y de Riogordo (Málaga).

CuAdro 4. Estratificación de una submuestra de hablantes femeninos del Proyecto Fordial

\begin{tabular}{|l|c|c|c|c|}
\hline Educación & Sin est. y prim. & Media & Superior & Total \\
\hline GENERACIONES & & & & \\
$1{ }^{\mathrm{a} G}$ & 4 & 4 & 4 & 12 \\
$2{ }^{\mathrm{a}} \mathrm{G}$ & 4 & 4 & 4 & 12 \\
$3^{\mathrm{a}} \mathrm{G}$ & 4 & 4 & 4 & 12 \\
Total & 12 & 12 & 12 & 36 \\
\hline
\end{tabular}

\subsection{Variables independientes de post-estratificación}

En el Apéndice 1 se incluye el Cuestionario Sociodemográfico y reticular, que resume y organiza sistemáticamente las hipótesis sobre las variables independientes a las que se les supone capacidad predictora sobre la variación lingüística en el contexto de la investigación de la inmigración rural en Málaga y Granada.

En particular, debe destacarse -además del efecto de las variables de estratificación mencionadas en la sección anterior- la influencia que se supone a: (1) las redes sociales consideradas como el mejor procedimiento para observar y analizar la integración en la estructura urbana o, contrariamente, la lealtad a la localidad de origen; (2) las actitudes individuales sobre ciertos indicadores de ruralidad y de urbanismo; (3) el contacto con los medios de comunicación ${ }^{12}$.

\subsubsection{Redes sociales}

Con las preguntas 23-33 del Cuestionario (Apéndice 1) y mediante el Generador de Nombres (Apéndice 2) se obtiene información sobre la red personal de los hablantes de la muestra. Se utilizan dos procedimientos complementarios:

a) Etnográfico: a través del Generador de Nombres $(\mathrm{GN})^{13}$ los hablantes estudiados nos proporcionan la información necesaria para dibujar su red personal y los atributos y demás rasgos sociales de los contactos mencionados (estatus, edad, sexo, etc.), así como las ca- 
racterísticas de la relación con el informante (intensidad, frecuencia, duración del vínculo, etc. $)^{14}$.

b) Sociológico: mediante las preguntas 23-33 del Cuestionario se interroga directamente al informante sobre su red personal. La intención es comparativa y busca la ulterior correlación con las variables lingüísticas. A partir de los datos surgidos de las preguntas se construyen escalas que miden directa o indirectamente la extensión, intensidad, multiplicidad, etc. de las redes personales de los hablantes; la fuerza o intensidad de sus vínculos, el grado de contacto y de vinculación emocional con la localidad de origen y de satisfacción con las redes urbanas.

Esta es la hipótesis más fuerte de la investigación y se combina, desde luego, con la información sociodemográfica de estratificación mencionada arriba $(\S 3.1)$ y con los datos sociales y psicosociales no estratificacionales: renta, ocupación, barrio de residencia, datos sociodemográficos de los padres, etc. (preguntas 6-17) ${ }^{15}$. Como se sabe, la interacción de los datos reticulares, sociales y psicosociales es uno de los fundamentos más importantes en la explicación de la variación lingüística (Milroy y Margrain, 1980; Villena y Requena 1996).

Las preguntas $36-40$ se refieren a la utilidad de la red social para los hablantes: se considera así la utilización por parte de los hablantes de la red de relaciones personales y los lazos débiles para obtener ciertas ventajas comunitarias (trabajo, acceso a servicios públi$\cos$ ), al margen de la función de solidaridad y cohesión interna que las redes tienen para sus miembros (Requena, 1991). Si el inmigrante encuentra utilidad a su red personal en la ciudad para alcanzar objetivos ajenos a la comunidad local de parientes y amigos, ello puede ser un indicador de integración y satisfacción en el nuevo contexto.

Por último, se han incluido dos preguntas (41-42) para medir el grado de segregación de los papeles conyugales en las parejas de hablantes. Como es sabido, la bibliografía reticular ha puesto de manifiesto una notable diferencia entre hombres y mujeres en cuanto a la importancia que tienen las redes personales en la vida social de los actores (Requena, 1995; Villena y Requena, 1996). El hecho de que las mujeres utilicen más la red social y dispongan de vínculos más intensos que los hombres está relacionado con la división de papeles en los hogares y con la diversificación y mayor extensión de las redes masculinas, ligada al mundo del trabajo en las comunidades locales tradicionales (Bott, 1957; Milroy, 1980). La hipótesis consiste, entonces, en relacionar la repartición de los papeles (segregados o compartidos), la estructura de la red personal (densa o laxa) y la lealtad a la variedad vernacular (concentrada o dispersa).

\subsubsection{Actitudes}

La relación del inmigrante con la estructura de los valores urbanos en la que se quiere integrar o que rechaza es una variable que se ha demostrado como fundamental para enten-

14 El GN (Apéndice 2) se rellena preguntando al informante por sus contactos y recabando la información personal y reticular de las personas nombradas. Cada fila del generador (por ej., 'sexo', 'frecuencia de reunión', etc.) es una variable que recibe el número correspondiente al contacto nombrado ('sexol', 'frecuencial', 'sexo2', 'frecuencia2', etc.). Los cálculos más frecuentes se efectúan mediante el cómputo de los valores de cada variable en el número total de contactos citados por el informante.

15 Estas preguntas (como las preguntas 1-15, destinadas a los datos de filiación y otras circunstancias) no se incluyen en el Apéndice 1, dado su carácter estandarizado. 
der los procesos que interesan aquí. Se trata de una información cualitativa que se puede obtener mediante cuestionario (preguntas 34-35) y que tiene bastantes precedentes (BortoniRicardo, 1985; Caravedo, 1990; Kerswill, 1994a; Marshall, 2001). Las escalas de ruralidad/ urbanismo se construyen basándose en respuestas a preguntas de cuestionario, mediante observaciones cualitativas del observador participante o a través de la combinación de ambos procedimientos. El "índice de urbanización" de Bortoni-Ricardo (1985: 162-169): "se basa en el promedio de la puntuación obtenida por los hablantes en siete variables consideradas como aspectos sintomáticos del grado de exposición de los inmigrantes a la cultura urbana" (ibid: : 169) ${ }^{16}$. Las variables seleccionadas en el estudio de Brasilia como indicadores de la transición rural / urbana fueron: (1) nivel educacional, (2) categoría profesional, (3) movilidad espacial, (4) participación en acontecimientos urbanos, (5) exposición a los medios de comunicación, (6) conciencia política y (7) dominio en el que el contacto se efectuó (ibid: 170). Otro ejemplo de interés es el índice complejo de Marshall (2001) aplicado en su estudio de un grupo de inmigrantes rurales en la Escocia urbana ${ }^{17}$.

\subsubsection{Exposición a los medios de comunicación}

La exposición de los hablantes a los medios de comunicación es un indicador notable de la integración en la cultura urbana de corriente dominante (Naro y Pereira, 1994). La relación de los individuos con los medios de comunicación es una información de gran interés -complementaria del nivel de instrucción formal- para conocer la integración de los hablantes en la cultura de corriente dominante en la comunidad. Este tipo de factores se ha empleado en bastantes investigaciones y proporciona bases explicativas de gran interés.

En el caso de la investigación etnográfica de la ciudad de Málaga (Villena, 2000; Cuevas, 2001), se incluyó en el cuestionario una pregunta destinada a la construcción de una escala para medir el grado y la calidad de la exposición de los hablantes a los medios de comunicación. Se trata de una escala entre 0-3, en la que los valores más bajos indican el menor contacto con los media y los más altos el más estrecho y, sobre todo, dan cuenta de la calidad

\footnotetext{
16 Cfr. Cuevas (2001: 64-68).

17 La escala (0-9) utilizada por Marshall (2001) (Menurb) mide la orientación del hablante con respecto al área local rural / área urbana y utiliza las siguientes cuestiones: $(0)$ indicios de orientación cultural positiva hacia la ciudad, manifestada, por ej., en el modo de vestir; (1) interés en la selección de programas de televisión o de radio relacionados con la ciudad y la vida urbana; (2) expectativas de trabajo futuro en el contexto urbano, frente a la tendencia a trabajar en el área local; (3) deseo de acceder a cierto desarrollo tecnológico (posesión de ordenador personal); (4) deseo de instalación definitiva en la ciudad y abandono del área local; (5) satisfacción con el contexto urbano; (6) percepción positiva de los habitantes de la ciudad; (7) abandono de la cocina tradicional a favor de la cocina internacional y de la comida rápida; (8) preferencia por el desarrollo de una carrera profesional y la ambición personal frente al deseo de paz y tranquilidad y una vida familiar apacible; (9) preferencia por el ocio en la ciudad, frente al tiempo libre dedicado a la exploración del campo. El resultado es una medida de cómo se percibe el hablante a sí mismo con relación a la comunidad rural / urbana; algo así como el modo de vida (en el sentido de HØjrup) compuesto (composite life mode). El hablante puede estar incluido en un modo de vida determinado por razones macrosociales (Milroy y Milroy, 1992), pero sus opiniones personales pueden llevarlo a posiciones contrarias a su propio grupo. Menurb pretende, pues, mostrar el grado de "urbanización mental" del hablante, puede ser cuantificado fácilmente y ser empleado como una herramienta analítica para la correlación con el uso lingüístico vernacular. La orientación mental positiva hacia el grupo local es un poderoso predictor del uso lingüístico, incluso allí donde las redes sociales dejan de serlo (Labov, 2001; Eckert, 1989, 2000; Villena, en prensa).
} 
de esta exposición: tipo de publicación que se lee, frecuencia; horas semanales de radio, tipos de programas; horas semanales de televisión, tipos de programas, etc. Así mismo, se tiene en cuenta la capacidad de comprensión y de evaluación crítica de los contenidos por parte de cada hablante. El grado de correlación de la exposición individual a los medios de comunicación con las variables fonológicas consideradas es fuerte y significativo. Como era de esperar, el grado de exposición a los medios se correlaciona positivamente $(.5450$, $\mathrm{p}=.000$ ) con las variables lingüísticas prestigiosas (por ej., la distinción de $/ \mathrm{s} /: / \theta /$ ), en tanto que la correlación es negativa $(-.3278, \mathrm{p}=.001 \mathrm{y}-.6660, \mathrm{p}=.000$, respectivamente, con la lenición de $/ \mathrm{t} / / \rightarrow \int \mathrm{y}$ la elisión de $/ \mathrm{x} / \rightarrow \varnothing$ ) con las variables estigmatizadas. La relación entre la exposición a los media y la educación y la edad de los sujetos es la que cabría esperar: positiva, bastante fuerte y muy significativa entre el grado de contacto con los medios de comunicación y los estudios de los hablantes $(.7886, \mathrm{p}=.000, \mathrm{~N}=136)$ y negativa entre estas dos y la edad $(-.4463, \mathrm{p}=.000, \mathrm{~N}=139$ con respecto a los estudios y $-.2354, \mathrm{p}=.006, \mathrm{~N}=135$ con respecto a los media $)^{18}$.

La pregunta 18 del Cuestionario recoge la información esencial para la construcción de escalas similares a la comentada.

\subsection{Variables lingüísticas}

El objetivo de la investigación consiste, como se explicó arriba, en estudiar la formación de nuevas variedades o modalidades derivadas a partir del contacto entre modalidades originarias de proceđencia rural en el contexto urbano (Caravedo, 1995: 500-506). De este modo, la integración o el aislamiento de los inmigrantes rurales en la estructura urbana es el punto central de atención desde el punto de vista explicativo. Se parte de los conocimientos adquiridos en el curso de las investigaciones urbanas previas en Málaga y Granada (Proyectos VUM y HAGA). En el primer acercamiento, el centro de atención está en la variación fonológica, pero debido a que el procedimiento de recolección de datos se basa en el empleo combinado de entrevistas lingüísticas semidirigidas y conversaciones libres, el corpus oral puede ser objeto ulterior de variados tipos de análisis.

El Cuestionario lingüístico, $C L$ (Apéndice 3) es el procedimiento ordenado de sistematización de las hipótesis sobre la variación fonológica y se integra en el Cuestionario general que está formado por el Cuestionario sociodemográfico y reticular, CSR (Apéndice 1) y el Generador de Nombres, GN (Apéndice 2). Se dibuja así un conjunto de cinco diferentes contextos conversacionales que funciona como variable independiente de la variación diafásica:

(1) Entrevista estructurada basada en el csR sobre la biografía personal, sociodemográfica y reticular del informante (Apéndice 1).

(2) Entrevista semidirigida o Conversación (c) basada en una red conversacional (conversational network) ${ }^{19}$ constituida por módulos sobre: desplazamientos, habitación, cultura doméstica, acontecimientos destacables de la biografía personal, etc. (Apéndice 3).

(3) Prueba de Respuestas ( $R$ ) basada en estímulos consistentes en dibujos que representan situaciones válidas para extraer de los informantes la realización de palabras o enunciados 
que contienen las variables fonológicas de interés en la investigación. Como se deduce de lo explicado arriba, las variables son las consonantes del sistema fonológico, especialmente, en la posición de ataque silábico ${ }^{20}$.

(4) Prueba de Lista de Palabras (LI). Se incluyen las mismas formas de (3) y otras diferentes de los mismos entornos. Se añaden aleatoriamente formas de entornos diferentes para control.

(5) Prueba de Lectura (LE).

El CL está formado, así pues, por tres pruebas específicas: $R, L I, L E$ que constituyen un estilo gráfico frente al estilo oral que se obtiene con la actuación lingüística de los informantes en sus respuestas a las preguntas del CSR y las conversaciones libres que suscita, así como, fundamentalmente, del registro de $C$.

\subsection{Observaciones finales}

Se recomienda trabajar con las submuestras de inmigrantes y el grupo rural de control a la vez, a partir del mismo anclaje. El procedimiento para seleccionar los individuos requeridos por las cuotas es el de "bola de nieve". Con cada informante se rellena el Generador de Nombres (GN). Esto permite unir información reticular paralela al proceso de selección de informantes y complementaria de la obtenida a través del Cuestionario Sociodemográfico (CSR).

La justificación del trabajo con respecto a los informantes se presenta de modo distinto según la muestra (urbana y rurbana / rural):

(1) Hablantes urbanos y rurbanos:

(i) Estudio de la integración urbana de los inmigrantes de los pueblos y su grado de satisfacción en la ciudad.

(ii) Uso de la lengua y sus diferencias (lealtad, deslealtad, etc.).

(2) Hablantes rurales:

(i) Estudio de las formas de vida en el mundo rural y pequeñas comunidades.

(ii) Estudio de la forma de hablar de la localidad y diferencias con otras localidades y con la ciudad.

Se registra la actuación lingüística completa de los informantes. Se recomienda grabación digital de todas las partes de la entrevista y, en todo caso, del Cuestionario Lingüístico (CL). Pueden hacerse entrevistas a dos informantes a la vez (por ej., parejas). Duración aproximada: 30 minutos de conversación + el tiempo necesario para terminar el resto de las partes.

20 El material de esta investigación, sin embargo, permite el estudio de otros fenómenos lingüísticos, como se apuntó arriba. En particular, la investigación de la variación del consonantismo en la posición de la coda silábica puede basarse en los registros de las entrevistas semidirigidas donde, como se sabe, la frecuencia de aparición de los segmentos de mayor interés es alta. La comparación de los resultados de estos estudios con otras investigaciones sobre las mismas poblaciones ofrece múltiples posibilidades (cfr. Moya y G. Wiedemann, 1995; Vida, 2003). 


\section{Referencias bibliográficas}

Abd-el-Jabad, H. (1986): "The emergence of an urban dialect in the Jordanian urban centres", IJSL, 61.

Andersen, H. (1988): "Center and periphery: Adoption, diffusion and spread". En Fisiak, J. (ed.): Historical dialectology. Berlín, Mouton, págs. 39-83.

Auer, P. (1988): "MHG î and $\hat{u}$ in the city dialect of Constance". En Auer, P. y A. di Luzio (eds.): Variation and convergence. Berlín, Walter de Gruyter, págs. 44-75.

Auer, P., B. Barden y B. Großkopf (1997): "Long-term linguistic accommodation and its sociolinguistic interpretation: Evidence from the inner-German migration after the Wende". En Mattheier, K. J. (ed.): Dialect migration in a changing Europe. Frankfurt, Peter Lang.

Auer, P. y F. Hinskens (eds.) (1996a): The convergence and divergence of dialects in Europe. Sociolinguistica 10. Tubinga, Max Niemeyer.

Auer, P. y F. Hinskens (1996b): "The convergence and divergence of dialects in Europe. New and not so new developments in an old area". En Auer y Hinskens (eds.), págs. 1-30.

Ávila, A. M. (1994): "Variación reticular e individual de s/z en el Vernáculo Urbano Malagueño: Datos del barrio de Capuchinos", Analecta Malacitana, 17, págs. 343-367.

Bortoni-Ricardo, S. M. (1985): The urbanisation of rural dialect speakers: A sociolinguistic study in Brazil. Cambridge CUP.

Bott, E. (1957): Family and social network. Londres: Tavistock, 1971 (Traducción esp. Madrid, Taurus 1990).

Caravedo, R. (1990): Sociolingüistica del español de Lima. Lima, Universidad Católica.

Caravedo, R. (1996): "Variedades en contacto: propuestas para una investigación del español de Perú", Signo y Seña (Revista del Instituto de Lingüística: Contactos y transferencias lingüisticas en Hispanoamérica. Buenos Aires, Universidad de Buenos Aires), núm. 6, págs. 493-511.

Carbonero, P. (1983): "Norma estándar y actitud sociolingüística". En Carbonero (2003), págs. 21-29.

Carbonero, P. (1985): “Aspectos sociolingüísticos sobre la nivelación en el español meridional". En Carbonero (2003), págs. 39-45.

Carbonero, P. (2003): Estudios de sociolingüística andaluza. Sevilla, Universidad.

Carbonero, P. et alii (1992): El habla de Jerez. Estudio sociolingüistico. Jerez, Ayuntamiento.

Cuevas Molina, I. (2001): Variación social, reticular e individual de las consonantes obstruyentes palatales y dentales en Nueva Málaga. Tesis Doctoral. Área de Lingüística General. Málaga: Universidad de Málaga.

Dressler, W. U. y R. Wodak (1982): "Sociophonological methods in the study of sociolinguistic variation in Viennese German", Language in Society, 11, págs. 339-370.

Eckert, P. (1989): "The whole woman: Sex and gender differences in variation", Language Change \& Variation, 1, págs. 245-268.

Eckert, P. (2000): Linguistic variation as social practice. Oxford, Blackwell.

Frago, J. A. (1993): Historia de las hablas andaluzas. Madrid, Arco/Libros.

García Marcos, F. J. (2002): Lenguaje e inmigración (I). Sociolingüística e inmigración. Granada, Granada Lingüística.

Hernández Sacristán, C. y R. Morant Marco (eds.) (1997): Lenguaje e inmigración. Valencia, Universidad.

Hinskens, F. (1996): Dialect levelling in Limburg. Structural and sociolinguistic aspects. Tubinga, Max Niemeyer.

Kerswill, P. E. (1994a): Dialects converging. Rural speech in rural Norway. Oxford, Clarendon Press.

Kerswill, P. E. (1994b): A new dialect in a new city: children's and adult's speech in Milton Keynes. Final Report. Project founded by the Economic and Social Research Council (1990-1994 R000232376). Reading. 
Kerswill, P. E. (1996): "Divergence and convergence of sociolinguistic structures in Norway and England". En Auer y Hinskens (eds.), págs. 90-104.

Kerswill, P. E. (2002): “Koineization and accommodation”. En Chambers, J, K., P. Trudgill y N. Schilling-Estes (eds.): The handbook of language variation and change. Oxford, Blackwell, 669-702. Kerswill, P. E. y A. Williams (2002): "Creating a new town koine: children and language change in Milton Keynes", Language in Society, 29, págs. 65-115.

Kerswill, P. E. y A. Williams (en prensa) "'Salience' as an explanatory factor in language change: evidence from dialect levelling in urban England". En M. C. Jones y E. Esch (eds.): Contactinduced language change. An examination of internal, external and non-linguistic factors. Berlín, Mouton / Walter de Gruyter.

Kroch, A. (1978): "Towards a theory of social dialect variation”, Language in Society, 7, págs. 17-36. Labov, W. (2001): Principles of linguistic change. Social factors. Oxford, Blackwell.

Lippi-Green, R. L. (1989): "Social network integration and language change in progress in a rural alpine village", Language in Society, 18, págs. 213-234.

López Morales, H. (1994): Métodos de investigación lingüística. Salamanca, Ediciones El Colegio de España.

Marshall, J. (2001). Understanding language change: an investigation of the influence of social factors on language change in a Scottish farming community. Tesis Doctoral inédita. Universidad de Reading.

Martínez, M. y J. A. Moya Corral (2000): "Reacciones actitudinales hacia la variación dialectal en hablantes granadinos", $L E A, 22 / 2$, págs. 137-160.

Mattheier, K. J. (1996): "Varietätenkonvergenz. Überlegungen zu einem Baustein einer Theorie der Sprachvariation". En Auer / Hinskens (eds.), págs. 31-52.

Mattheier, K. J. (ed.) (2000): Dialect and migration in a changing Europe. Frankfurt, Peter Lang.

Milroy, L. (1980): Language and social networks. Oxford, Blackwell, $1987^{2}$.

Milroy, J. (1992): Linguistic variation and change. Oxford, Blackwell.

Milroy, L. y S. Margrain (1980): "Lealtad lingüística vernacular y red social". En Requena, F. (ed.) (2003): Análisis de redes sociales. Orígenes, teorias y aplicaciones. Madrid: CIS, págs. 417-455 (orig. en Language in Society, 9 (1980), págs. 43-70).

Milroy, L. y J. Milroy (1992): "Social network and social class: Toward an integrated sociolinguistic model", Language in Society, 21, págs. 1-26.

Molina Serrato, F. M. (2003): "La acomodación a la norma granadina. A propósito de un grupo de alhameños instalados en Granada". En Moya Corral, J. A. y M. I. Montoya Ramírez (eds.) (2003): Variación lingüística y enseñanza de la lengua española (Actas de las VIII Jornadas sobre la enseñanza de la Lengua Española). Granada, Universidad, págs. 292-305.

Molina Serrato, F. M. y Moya Corral, J. A. (2002): “Distinción e igualación de /s/ y / / / en Alhama de Granada". En Moya Corral, J. A. y M. I. Montoya Ramírez (eds.) (2003): Gramática y enseñanza de la lengua española. Granada, Universidad, págs. 275-281.

Mondéjar, J. (1991): Dialectologia andaluza. Estudios. Granada, Editorial Don Quijote (Anejo 36 de Analecta Malacitana, Málaga, 2001²).

Mondéjar, J. (1995): "La norma lingüística del español y la pretendida norma de las hablas andaluzas", Analecta Malacitana, 18, págs. 29-40.

Moreno Fernández, F. (1993): "Proyecto para el estudio del Español de España y América (PreseEA). Presentación", Lingüística, 5, págs. 268-271.

Moreno Fernández, F. (1996): "Metodología del 'Proyecto para el estudio del Español de España y de América (PreseeA)". Lingüistica, 8 (1996), págs. 257-287.

Moya Corral, J. A. (1997): "Desarraigo social y cambio lingüístico. El ejemplo de Granada". En Narbona, A. y M. Ropero (eds.): El habla andaluza. Actas del Congreso de Habla Andaluza (Sevilla, 3-7 marzo 1997). Sevilla, Universidad, págs. 623-634.

Moya Corral, J.A. (2000): "Migration et changement linguistique à Grenade (Espagne)". En Mattheier, K. J. (ed.), págs. 25-41. 
Moya Corral, J. A. (2003): "La irradiación de la norma lingüística de Granada hacia su área metropolitana". En Morales Raya, R. (ed.): Homenaje a la profesora María Dolores Tortosa Linde. Granada, Universidad, págs. 393-402.

Moya Corral, J. A. y E. García Wiedemann (1985): El habla de Granada y sus barrios. Granada, Universidad.

Naro, A. J. y Pereira Scherre (1994): "Contact with media and linguistic variation". En Arnold, J. et alii (eds.): Sociolinguistic variation. Data, Theory and Analysis (Selected Papers from NWAV23, Stanford). Stanford, págs. 223-228.

Nordberg, B. (ed.) (1994): The sociolinguistics of urbanisation. The case of the Nordic Countries. Berlín / Nueva York, Walter de Gruyter.

Requena Santos, F. (1991): Redes sociales y Mercado de trabajo. Madrid: CIS / Siglo XXI.

Requena Santos, F. (1995): "Determinantes estructurales de las redes sociales en los hombres y las mujeres", Papers 45, págs. 33-41.

Requena Santos, F. (1996): Redes sociales y cuestionarios. Madrid, CIS.

Requena, F. y A.M. Ávila (2002): "Redes sociales y sociolingüística", Estudios de Sociolingüística, 3 , págs. 71-90.

Trudgill, P. (1974): The social differentiation of English in Norwich. Cambridge, CUP.

Trudgill, P. (1986): Dialects in contact. Oxford, Blackwell.

Trudgill, P. (1992): "Dialect typology and social structure". En Hakon Jahr, E. (ed.): Language contact and language change. Berlín, Mouton/ Walter de Gruyter, págs. 195-212.

Trudgill, P. (1994): "Language contact and dialect contact in linguistic change". En Kotsinas, U.B. y J. Helgander (eds.): Dialectkontact, språchkontakt och språförändring i Norden. Föredrag från ett forskarsymposium. Estocolmo, MINS 40, Institutionen för nordinska språk, Stockholm Universitet, págs. 13-22.

Trudgill, P. (1996): "Dialect typology: Isolation, social network and phonological structure". En Guy, G. R. et alii: Towards a social science of language (Vol. l). Amsterdam / Filadelfia, John Benjamins, págs. 3-22.

Trudgill, P. (2002): "Linguistic and social typology". En Chambers, J. K. y P. Trudgill y N. SchillingEstes (eds.): The handbook of language variation and change. Oxford, Blackwell, 707-728.

Vida Castro, M. (2003): Restricciones universales sobre la variación de /s/ en la distensión silábica. Tesis Doctoral. Área de Lingüística General de la Universidad de Málaga. Málaga, Universidad. Villena Ponsoda, J. A. (1994): La ciudad lingüística. Granada, Universidad.

Villena, Ponsoda J.A. (1996): "Convergence and divergence in a standard-dialect continuum: Networks and individuals in Malaga". En Auer y Hinskens (eds.), págs. 112-137.

Villena Ponsoda, J. A. (1997): "Convergencia y divergencia dialectales en el continuo sociolingǘstico andaluz: datos del vemáculo urbano malagueño", Lingüística Española Actual, 19, págs. 83-125.

Villena Ponsoda, J. A. (2000): "Identidad y variación lingüística: Sistema y síntoma en el español andaluz". En Bossong, G. y F. Báez de Aguilar (eds.): Identidades lingüisticas en la España cutonómica. Frankfurt / Madrid, Vervuert / Iberoamericana, págs. 107-150.

Villena Ponsoda, J. A. (2001): La continuidad del cambio lingüistico. Granada, Universidad.

Villena Ponsoda, J. A. (2002): "Tipología de sistemas fonológicos y variación sociolingüistica en el español de Andalucía". En Martínez González, A. (ed.): Las hablas andaluzas ante el siglo XXI. Almería, Instituto de Estudios Almerienses, págs. 189-213.

Villena Ponsoda, J. A. (2003): "Igualdad y desigualdad social como factores condicionantes del uso lingüístico. Variación estratificacional, reticular e individual en el español de Andalucía". En El habla andaluza. El español hablado en Andalucía. Estepa, Ayuntamiento de Estepa, págs. 73-104.

Villena Ponsoda, J. A. (en prensa): "How similar are people who speak alike? An interpretive way of using social networks in social dialectology research". En Kerswill, P. E. / P. Auer y F. Hinskens (eds.): Dialect variation and change in Europe. Cambridge, CUP.

Villena Ponsoda, J. A. y F. Requena Santos (1996): "Género, educación y uso lingüístico: la variación social y reticular de s y z en la ciudad de Málaga", Lingüistica 8, págs. 5-48. 


\section{Apéndice 1 \\ Cuestionario sociodemográfico y reticular}

Como se ha indicado ( $\$ 3.1$ ), las variables de estratificación son la edad, el sexo, los estudios, el lugar de residencia familiar (rural, urbana) y, en el último caso, el grado de contacto con la localidad rural de procedencia. Las preguntas 1-17 del CSR están dedicadas a obtener esta información. Se incluyen, asimismo, preguntas sobre variables de post-estratificación útiles para la elaboración de las escalas de clase socioeconómica (ESE): renta familiar, ocupación, barrio de residencia; para la elaboración de la biografía sociolingüística del hablante: localidad de procedencia, edad de llegada a la ciudad, tiempo de residencia, ocupación e instrucción de los padres del hablante, etc. El resto de las preguntas (18-40) se relaciona a continuación.

18. Exposición a los medios de comunicación. Rodee con un círculo el número correspondiente a la opción que más se acerque a sus características. Nota: el entrevistador puede dar detalles sobre el tipo de programa, con ejemplos ilustrativos sobre a qué se refiere con "periódico local", "programa cultural en radio", etc.

Libros (0-4) $\quad$ Periódicos (0-8)
\begin{tabular}{|l|l|l|l|}
\hline & & & \\
\hline
\end{tabular}

\begin{tabular}{|l|l|l|l|l|l|}
\hline Libros al año: & 0 Ninguno & 1 Alguno & 2 Más de cinco & 3 Más de diez & 4 Más de veinte \\
\hline Periódicos locales & 0 Nunca & 1 Alguna vez & $\begin{array}{l}2 \text { Al menos un día } \\
\text { a la semana }\end{array}$ & $\begin{array}{l}3 \text { Varios días a } \\
\text { la semana }\end{array}$ & 4 Todos los días \\
\hline Periódicos nacionales & 0 Nunca & 1 Alguna vez & $\begin{array}{l}2 \text { Al menos un día } \\
\text { a la semana }\end{array}$ & $\begin{array}{l}3 \text { Varios días a } \\
\text { la semana }\end{array}$ & 4 Todos los días \\
\hline $\begin{array}{l}\text { Programas de TV: } \\
\text { noticias, documentales }\end{array}$ & 0 Nunca & 1 Alguna vez & $\begin{array}{l}2 \text { Al menos un día } \\
\text { a la semana }\end{array}$ & $\begin{array}{l}3 \text { Varios días a } \\
\text { la semana }\end{array}$ & 4 Todos los días \\
\hline $\begin{array}{l}\text { Programas de TV: } \\
\text { noticias del corazón } \\
\text { y similar }\end{array}$ & 0 Todos los días & $\begin{array}{l}1 \text { Varios días a } \\
\text { la semana }\end{array}$ & $\begin{array}{l}2 \text { Al menos un día } \\
\text { a la semana }\end{array}$ & 3 Alguna vez & 4 Nunca \\
\hline $\begin{array}{l}\text { Programas de radio: } \\
\text { noticias, culturales }\end{array}$ & 0 Nunca & 1 Alguna vez & $\begin{array}{l}2 \text { Al menos un día } \\
\text { a la semana }\end{array}$ & $\begin{array}{l}3 \text { Varios días a } \\
\text { la semana }\end{array}$ & 4 Todos los días \\
\hline
\end{tabular}


19. Trabajo:

0 Vive y trabaja en el pueblo siempre

1 Vuelve a su casa en el pueblo todos los días para comer y dormir

2 Vuelve al pueblo todos los días para dormir

3 Vueive a su casa en el pueblo solo los fines de semana

4 Vuelve a su casa en el pueblo solo en vacaciones

5 Vive en la ciudad y vuelve al pueblo solo alguna vez (de uvas a peras)

6 Ya no tiene casa en el pueblo y cuando va se queda en casa de familiares

7 Vive en el pueblo

20. Matrimonio. Marque (x) la opción que corresponda:

¿Está casado o tiene pareja estable? síno

21. Su pareja, ¿nació en la misma localidad que usted? Si no es así, indique dónde nació: síno

22. ¿Viven sus hijos en su misma localidad de residencia? Marque (x) la opción que corresponda: Síno

Hijo $1^{\circ}$

Hijo $2^{\circ}$

Hijo $3^{\circ}$

Hijo $4^{\circ}$

Hijo $5^{\circ}$

23. Información reticular. Piense ahora en las personas (al margen de la familia nuclear: pareja, hijos) con las que tiene CONTACTOS FRECUENTES; es decir personas con las que tiene TRATO PERSONAL FRECUENTE. Indique solo sus nombres de pila precedidos de un número en la tabla siguiente (por ejemplo, 1 Juan, 2 Pepe en la columna 1. ${ }^{\mathrm{a}}, 1$ Juan 3 María en la columna 2. y así sucesivamente). Si se conocen y se tratan entre sí, indíquelo abajo (Nota). No le importe repetir el nombre de la persona si coincide que tiene frecuente relación con ella, que es, por ejemplo, a la vez, vecino y pariente o compañero y amigo. Por ejemplo:

\begin{tabular}{|c|c|c|c|}
\hline Compañeros de trabajo & Parientes & Vecinos & Más de una relación \\
\hline 1 Antonio & 1 Antonio & & amigos $1,2,3$ \\
\hline 2 Juan & 2 Juan & & vecinos \\
\hline 3 Pepe & 3 Pepe & & compañeros $1,2,3$ \\
\hline 4 Juanjo & 4 María & & parientes \\
\hline
\end{tabular}

Nota. Ofrezca detalles: Juan y Pedro son amigos y compañeros de trabajo del informante; se conocen y se tratan diariamente, etc.

Compañeros de trabajo Amigos

Parientes

Vecinos

Más de una relación

Detalles:

24. Fuerza de los vínculos. Indique ahora los nombres de las personas con las que tiene plena confianza, aunque no las vea diariamente, y a las que, si fuese necesario, pediría un favor importante. Escriba sus nombres en la casilla que corresponda como se indica en el ejemplo siguiente. Añada el núm. como en la pregunta anterior (23). La casilla debajo de la línea más gruesa es para el investigador. 


\begin{tabular}{|l|l|}
\hline 0 Compañeros de trabajo & 1 Antonio, 2 Juan, 3 Pepe \\
\hline 1 Vecinos & \\
\hline 2 Amigos & 1 Antonio, 2 Juan, 3 Pepe, 4 Pilar \\
\hline 3 Amigos íntimos & 4 Pilar \\
\hline 4 Parientes & 1 Gabriel \\
\hline 5 Más de una relación & 1234 \\
\hline
\end{tabular}

\begin{tabular}{|l|l|}
\hline 0 Compañeros de trabajo & \\
\hline 1 Vecinos & \\
\hline 2 Amigos & \\
\hline 3 Amigos intimos & \\
\hline 4 Parientes & \\
\hline 5 Más de una relación & \\
\hline
\end{tabular}

25. Satisfacción con la red social. ¿Está usted satisfecho con las personas a las que trata frecuentemente y a las que se puede dirigir en caso de necesidad? Marque $(x)$ la opción que corresponda:

\begin{tabular}{l|l}
0 Nada & $\square$ \\
1 Un poco \\
2 Bastante \\
3 Mucho
\end{tabular}

26. Las personas con las que se trata son (marque la opción que corresponda):

0 Contactos solo en el pueblo

1 Contactos en el pueblo y en otros pueblos

2 Contactos en el pueblo y en la ciudad

3 Contactos solo en la ciudad

4 Contactos en la ciudad y en otras ciudades

5 Contactos solo en otras ciudades

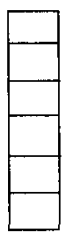

27. Satisfacción con la comunidad. ¿Está usted satisfecho con cómo le ha ido la vida en Málaga / en el pueblo? Marque $(\mathrm{x})$ la opción que corresponda:

0 Fatal
1 Muy mal
2 Mal
3 Regular
4 Bien
5 Muy bien

\begin{tabular}{|l|l|}
\hline Ciudad & Pueblo \\
\hline & \\
\hline & \\
\hline & \\
\hline & \\
\hline & \\
\hline & \\
\hline
\end{tabular}


28. Las personas a las que conoce y trata con frecuencia (cfr. pregunta 23), ¿se conocen entre sí? Marque (x) la opción que corresponda. Indique los nombres.

0 No. No se conocen

1 Solo algunas se conocen

2 Casi todas se conocen

3 Todas se conocen

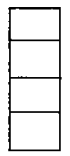

Nombres: $\quad 1$ :

2:

29. Las personas a las que conoce y trata con frecuencia, ¿se TRATAN ENTRE si? Marque (x) la opción que corresponda. Indique los nombres.

0 No. No se tratan

1 Solo algunas se tratan

2 Casi todas se tratan

3 Todas se tratan

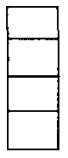

Nombres: 1 :

2:

30. Las personas con las que más le gusta estar son:

0 Del pueblo

1 Del pueblo y de la ciudad

2 De la ciudad

3 De la ciudad y de fuera de la ciudad

4 De fuera de la ciudad

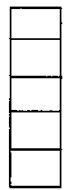

31. Densidad (0-7). Marque (x) la respuesta que corresponda en cada una de las preguntas siguientes:

1. Las personas a las que trata con frecuencia se conocen entre sí

2. Las personas a las que trata con frecuencia se tratan entre sí

3. ¿Tiene usted en cuenta lo que piensan esas personas de sus propias decisiones antes de tomarlas (comprar un piso, etc.)?

4. ¿Les consulta antes de tomar una decisión?

5. En caso de necesidad, ¿podría usted reunirlos a todos para algo importante?

6. ¿Se reúne usted con todos eilos alguna vez?

7. ¿Se reúne usted con todos periódicamente?

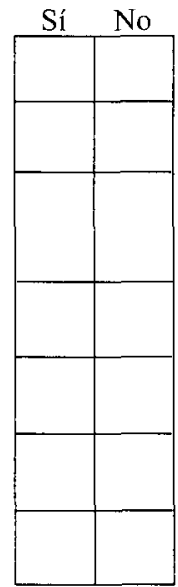


32. Multiplicidad (0-6). Marque (x) la respuesta que corresponda en cada una de las preguntas siguientes:

1. La mayoría de sus vecinos trabaja en el mismo sitio que usted (más de dos)

2. Se ve, sale usted en sus ratos de ocio o se visita con compañeros de trabajo

3. Se ve, sale usted en sus ratos de ocio o se visita con vecinos

4. En el vecindario viven sus parientes (más de dos)

5. Sus amigos más íntimos viven en el vecindario

6. Algunos de sus amigos más íntimos son parientes suyos (más de dos)

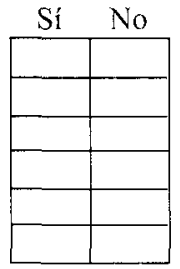

33. Fuerza de los vínculos (0-4). Usted pediría un favor muy importante (marque la respuesta que corresponda en cada una de las preguntas siguientes):

1. Solo a sus familiares inmediatos (mujer, padres, hijos, etc.)

2. Solo a algunas de las personas a las que trata con frecuencia

3. A todas las personas a las que trata con frecuencia

4. A todas las personas a las que conoce

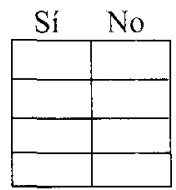

34. Ruralidad (0-7). Marque (x) la respuesta que corresponda en cada una de las preguntas siguientes. La pregunta 7 es para el entrevistador.

1. Vive en el pueblo o en la ciudad en zona periurbana (casa aislada con terreno)

2. Tiene en su casa de la ciudad o del pueblo un sitio donde tener gallinas, conejos...

3. Trabaja en la agricultura o la ganadería (aunque sea como afición)

4. Se iría / irá (o se quedará siempre) a vivir definitivamente al pueblo

5. Considera que las costumbres de la ciudad son peores que las del pueblo

6. Cuando tiene tiempo libre lo pasa en el pueblo

7. Vestido: viste como un campesino

\begin{tabular}{l|l} 
Sí & No \\
\hline & \\
\hline & \\
\hline & \\
\hline & \\
\hline & \\
\hline & \\
\hline & \\
\hline
\end{tabular}

35. Modernidad / urbanismo. Marque $(x)$ la respuesta que corresponda en cada una de las preguntas siguientes:

1. Vive en la ciudad

2. Le gustaría trasladarse a vivir al centro

3. Considera que las costumbres de la ciudad son mejores que las del pueblo

4. Tiene ordenador en su casa

5. Pasa el tiempo libre en la ciudad (cine, discotecas, etc.)

6. Le encanta que nadie lo conozca en la ciudad

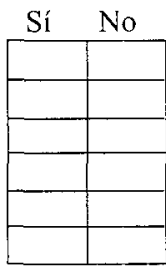

36. Utilidad de la red. ¿Cómo encontró el trabajo que tiene?

1. Información oficial o pública (oficinas, periódicos...)

2. Se dirigió directamente a la empresa

3. Por medio de familiares, amigos, conocidos, etc.

4. Otros

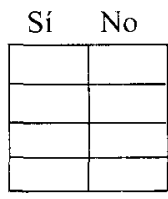


37. Utilidad de la red. ¿Qué contacto utilizó para encontrar el trabajo? Marque (x) la respuesta que corresponda en cada una de las preguntas siguientes:

1. Por medio de familiares

2. Por medio de vecinos o compañeros de trabajo

3. Por medio de un amigo

4. A través del amigo de un amigo

5. Por medio de un conocido

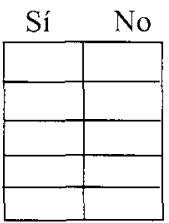

38. Utilidad de la red. ¿Cómo consigue enchufes para solucionar problemas con la administración (hospitales, seguridad social, educación, etc.)? Marque $(\mathrm{x})$ la respuesta que corresponda en cada una de las opciones siguientes:

1. Nunca busco a personas conocidas para eso

2. Por medio de familiares

3. Por medio de amigos

4. Por medio de vecinos

5. Por medio del amigo de un amigo

6. Por medio de un conocido

7. Otros

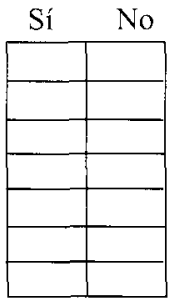

39. Segregación de papeles conyugales. Indique quién realiza las tareas en la casa: el hombre (1), la mujer (2) u otras personas (3), tal y como se hace en el ejemplo siguiente:

\begin{tabular}{|l|c|c|c|c|}
\hline & $\begin{array}{c}\mathrm{H} \\
(1)\end{array}$ & $\begin{array}{c}\mathrm{M} \\
\text { (2) }\end{array}$ & $\begin{array}{c}\text { H y M } \\
(3)\end{array}$ & $\begin{array}{c}\text { Otros } \\
(4)\end{array}$ \\
\hline 1 Hacer la cama & & & & \\
\hline 2 Fregar los platos & & $\mathrm{X}$ & & \\
\hline 3 Hacer la comida & & & $\mathrm{X}$ & \\
\hline 4 Llevar los niños al colegio & & & & $\mathrm{X}$ \\
\hline 5 Hacer la compra & & & & \\
\hline 6 Barrer y fregar & & & & \\
\hline 7 Ayudar a los niños con las tareas del colegio & & & & \\
\hline
\end{tabular}

\begin{tabular}{|l|l|l|l|l|}
\hline & $\mathrm{H}$ & $\mathrm{M}$ & $\mathrm{H}$ y M & Otros \\
\hline 1 Hacer la cama & & & & \\
\hline 2 Fregar los platos & & & & \\
\hline 3 Hacer la comida & & & & \\
\hline 4 Llevar los niños al colegio & & & & \\
\hline 5 Hacer la compra & & & & \\
\hline 6 Barrer y fregar & & & & \\
\hline 7 Ayudar a los niños con las tareas del colegio & & & & \\
\hline
\end{tabular}

40. Segregación de papeles. Su pareja y usted (marque la respuesta que corresponda en cada una de las opciones siguientes):

1 Salen siempre juntos con amigos comunes

2 Solo salen juntos con amigos comunes a veces

3 Nunca salen juntos. Cada uno tiene sus propios amigos

\begin{tabular}{c|c|}
\multicolumn{1}{c}{ Si } & No \\
\hline & \\
\hline & \\
\hline & \\
\hline
\end{tabular}


Apéndice 2. Generador de nombres

\begin{tabular}{|c|c|c|c|c|}
\hline Nombre o inicial & & & & \\
\hline Nombre $\mathrm{N}^{\mathrm{o}}$ & & & & \\
\hline SEXO & & & & \\
\hline Hombre & 1 & 1 & 1 & 1 \\
\hline Mujer & 2 & 2 & 2 & 2 \\
\hline Ve a esa persona sola & 1 & 1 & 1 & 1 \\
\hline La ve con su cónyuge & 2 & 2 & 2 & 2 \\
\hline Indistintamente & 3 & 3 & 3 & 3 \\
\hline Es mi cónyuge & 4 & 4 & 4 & 4 \\
\hline No está casado & 5 & 5 & 5 & 5 \\
\hline SE REÚNE CON ELLA & & & & \\
\hline En mi casa & 1 & 1 & 1 & 1 \\
\hline En su casa & 2 & 2 & 2 & 2 \\
\hline En ambas casas & 3 & 3 & 3 & 3 \\
\hline En otros sitios & 4 & 4 & 4 & 4 \\
\hline En la calle & 5 & 5 & 5 & 5 \\
\hline Indistintamente & 6 & 6 & 6 & 6 \\
\hline LE PEDIRÍA UN FAVOR & & & & \\
\hline 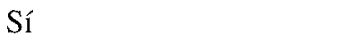 & 1 & 1 & 1 & 1 \\
\hline No & 2 & 2 & 2 & 2 \\
\hline FRECUENCIA DE REUNIÓN & & & & \\
\hline Diariamente & 1 & 1 & 1 & 1 \\
\hline Semanalmente & 2 & 2 & 2 & 2 \\
\hline Mensualmente & 3 & 3 & 3 & 3 \\
\hline Cada 3 meses & 4 & 4 & 4 & 4 \\
\hline Cada 6 meses & 5 & 5 & 5 & 5 \\
\hline Más de 6 meses & 6 & 6 & 6 & 6 \\
\hline TIPO DE RELACIÓN & & & & \\
\hline Pariente & 1 & 1 & 1 & 1 \\
\hline Conocido & 2 & 2 & 2 & 2 \\
\hline Amigo & 3 & 3 & 3 & 3 \\
\hline Comp. de trabajo & 4 & 4 & 4 & 4 \\
\hline Vecino & 5 & 5 & 5 & 5 \\
\hline Más de una relación & 6 & 6 & 6 & 6 \\
\hline ¿DÓNDE VIVE? & & & & \\
\hline$<10 \mathrm{~min}$ & 1 & 1 & 1 & 1 \\
\hline$<30 \mathrm{~min}$ & 2 & 2 & 2 & 2 \\
\hline$>30<60 \mathrm{~min}$ & 3 & 3 & 3 & 3 \\
\hline De $1 \mathrm{~h}$ a $2 \mathrm{~h}$ & 4 & 4 & 4 & 4 \\
\hline$>$ de 2 horas & 5 & 5 & 5 & 5 \\
\hline Fuera de ciudad & 6 & 6 & 6 & 6 \\
\hline En mi casa & 7 & 7 & 7 & 7 \\
\hline OCUPACIÓN (Código Requ & & & & \\
\hline ESTUDIOS & 0 & $\overline{0}$ & 0 & 0 \\
\hline & 1 & 1 & 1 & 1 \\
\hline & 2 & 2 & 2 & 2 \\
\hline & 3 & 3 & 3 & 3 \\
\hline
\end{tabular}




\section{Apéndice 3 \\ Cuestionario lingüístico}

\section{A. Entrevista semidirigida}

Conversación ( $\cong 30^{\prime}$ ) con el o los informantes sobre su biografía y sus circunstancias personales y familiares: trabajo, localidad, costumbres, etc. Las narraciones de los informantes no se interrumpen; tampoco los diálogos, en el caso de que sean más de uno. En el curso de la conversación se introducen las preguntas del siguiente guión conversacional:

1. ¿Cómo se desplaza a su trabajo? Si usa el autobús o el tren o el vehículo particular. Hable de él. ¿Cómo es? ¿Cuánto lo usa? ¿Qué opina de su uso?

- Relate una anécdota sobre el vehículo.

- Cuente algún suceso grave o curioso ocurrido a usted o a algún familiar o amigo.

- ¿Sabe algún chiste sobre coches?

2. Hable de su casa en la ciudad / pueblo. ¿Cómo es? ¿Cómo la consiguió? Si no tiene, ¿cómo le gustaría que fuera?

- ¿Cuáles son las comidas más frecuentes en el pueblo / barrio? Describa las que hace o consume y dónde. Comidas del pueblo y de la ciudad; de antes y de ahora. Opiniones.

- Lo mismo sobre las bebidas.

3. ¿Qué desayuna? ¿A qué hora? ¿En los descansos del trabajo? Describa un desayuno típico en su barrio / pueblo ¿,Sabe algún chiste o historia sobre comidas?

4. Comidas típicas de los pueblos ¿Están desapareciendo? La matanza. Los productos de la matanza. Cuente qué productos se hacen / hacían en su pueblo o en el de sus padres.

- Indique qué productos le gustan más de la matanza.

- Historias y anécdotas.

- Chistes.

5. Boda. Recuerdos de su boda. Proyecto de su boda. Opinión sobre el matrimonio. Chistes de bodas y similares.

6. Utensilios antiguos y modernos para la preparación de la comida y para su consumo (navaja, cuchara, cucharón, jarra, etc.).

\section{B. Respuestas a los dibujos}

El informante no debe ver esta parte; el estímulo es únicamente el dibujo correspondiente (Cuadro 5).

\begin{tabular}{|lllll|}
\hline $\mathrm{s} / \mathrm{z}$ & $\mathrm{x}$ & $\mathrm{f}$ & $\mathrm{ch}$ & $\mathrm{y} / 1 \mathrm{l}$ \\
\hline casa & teja & gafas & hacha & paella \\
taza & caja & cafetera & flecha & silla \\
mesa & & & & mella \\
cerveza & & & & rayas \\
\hline
\end{tabular}


Cuadro 5. Proyecto Fordial. Dibujos

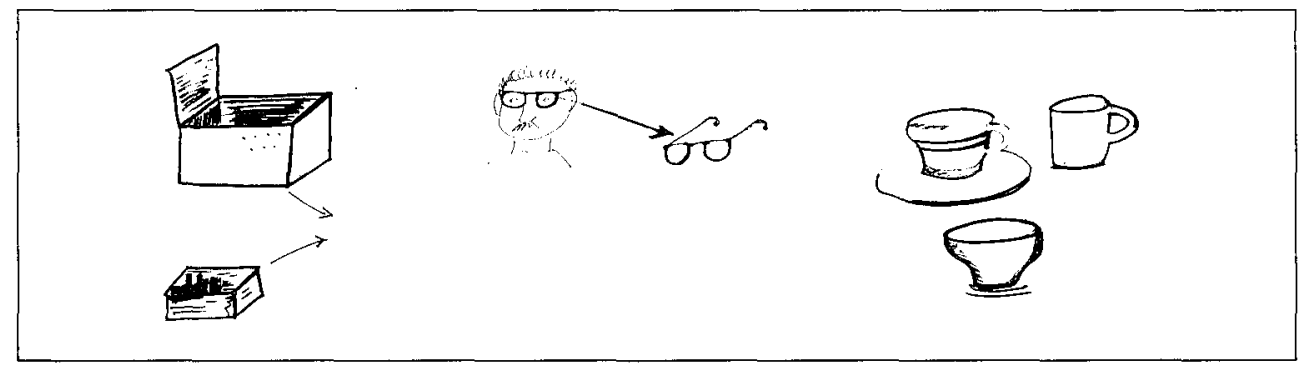

\section{Listas de palabras}

Contrólese el ritmo de lectura, que debe ser lento. Las palabras sombreadas son del grupo de control.

$\begin{array}{llll}\text { lápiz } & \text { café } & \text { vaso } & \text { mano } \\ \text { chorizo } & \text { cuchillo } & \text { puerta } & \text { jarra } \\ \text { calle } & \text { jamón } & \text { silla } & \text { alpargata } \\ \text { mesa } & \text { filo } & \text { fuera } & \text { leche } \\ \text { morcilla } & \text { hoja } & \text { navaja } & \text { pollo } \\ \text { amigo } & \text { cuchara } & \text { cerveza } & \text { vino } \\ \text { fuego } & \text { sopa } & \text { patata } & \text { raya } \\ \text { mella } & \text { casa } & \text { paella } & \text { gafas } \\ \text { teja } & \text { loma } & \text { hacha } & \text { cafetera } \\ \text { mesa } & \text { flecha } & \text { peña } & \text { caja } \\ \text { remo } & \text { cama } & \text { cerveza } & \\ & & & \\ & & & \\ \text { lápiz } & \text { café } & \text { vaso } & \text { mano } \\ \text { chorizo } & \text { cuchillo } & \text { puerta } & \text { jarra } \\ \text { calle } & \text { jamón } & \text { silla } & \text { alpargata } \\ \text { mesa } & \text { filo } & \text { fuera } & \text { leche } \\ \text { morcilla } & \text { hoja } & \text { navaja } & \text { pollo } \\ \text { amigo } & \text { cuchara } & \text { cerveza } & \text { vino } \\ \text { fuego } & \text { sopa } & \text { patata } & \text { raya } \\ \text { meila } & \text { casa } & \text { paella } & \text { gafas } \\ \text { teja } & \text { loma } & \text { hacha } & \text { cafetera } \\ \text { mesa } & \text { flecha } & \text { peña } & \text { caja } \\ \text { remo } & \text { cama } & \text { cerveza } & \end{array}$




\section{Lectura}

La casa que yo tenía en mi pueblo era antigua: con tejado de tejas rojas; parecía una caja de muñecas. Me sentaba a la puerta en mi silla preferida frente a la mesa delante de una cerveza fresquita y de un plato de paella y era la persona más feliz del mundo. Después me tomaba una taza de café o un vaso de leche, me ponía las gafas y me leía el periódico o me quedaba mirando a la gente que pasaba por la calle. 